\title{
LAS BASES SOCIALES \\ DE LA IDENTIDAD DUAL: \\ EL CASO VALENCIANO ${ }^{1}$
}

\author{
Xavier Coller \\ Rafael Castelló \\ Universitat de València
}

Yale University y Universidad de Alicante

\begin{abstract}
RESUMEN
Las teorías sobre nacionalismo e identidades colectivas, especialmente la escuela neoinstitucionalista, prevén la emergencia y consolidación de las identidades regionales como consecuencia de la federalización de los estados. Es más probable que este fenómeno ocurra cuando las condiciones políticas, culturales y/o económicas promueven un cierto sentimiento de diferenciación. El caso valenciano se desvía de esta presunción. En lugar de reforzarse la identidad periférica (regional o nacional), se consolida una identidad múltiple en la que se combinan los referentes colectivos valencianos y españoles. Este trabajo examina las bases sociales de esta identidad dual y desarrolla un modelo explicativo de este fenómeno que merece una atención mayor como resultado del proceso de descentralización de los estados.
\end{abstract}

${ }^{1}$ Los autores desean agradecer los valiosos comentarios de Juan Linz (Yale University), Eva Ponte (UC Berkeley), José Ramón Montero (Fundación March), Glenn Yamagata (Yale University), Eduardo López-Aranguren (Universidad Carlos III), Enric Martínez (Universidad Pompeu Fabra), y a los participantes en el grupo de «identidades colectivas» reunido en A Coruña en el IV Congreso de Sociología. Nuestro agradecimiento también al Centro de Investigaciones Sociológicas por permitirnos utilizar los datos del Estudio 2228, realizado por el CIS entre noviembre y diciembre de 1996. El primer autor desea agradecer la generosidad económica de la Fundación Bofill al sufragar un estudio más amplio del que esta «nota de investigación» es una parte.

\section{Reis}




\section{INTRODUCCIÓN}

Hace veinte años que España se dotó de un sistema político democrático y de una estructura territorial autonómica que, siguiendo a diversos autores, podríamos calificar de casi federal o de federalizante (García Ferrando et al., 1994; Moreno, 1997). Este modelo de articulación territorial ha consolidado el caso español como paradigma de Estado democrático multilingüe y multinacional (Linz, 1989). De acuerdo con la teoría neoinstitucionalista, este proceso de federalización debería haber originado un reforzamiento de las identidades colectivas periféricas como efecto de las políticas de las instituciones de autogobierno regional (Brubaker, 1996). Se puede sospechar que tal reforzamiento es más acusado en aquellas áreas con un lengua diferente al castellano y con cierta experiencia de autogobierno, ya sea reciente o histórica. La mayoría de las investigaciones realizadas han demostrado que éste es el caso de las Comunidades Autónomas con lengua propia, como son Cataluña, el País Vasco, Galicia, Navarra y, en menor medida, las Islas Baleares (Herranz, 1996; Moreno, 1997).

Dadas las condiciones económicas, culturales, históricas y lingüísticas de la Comunidad Valenciana ${ }^{2}$, la mayoría de las teorías del nacionalismo hubieran predicho un comportamiento similar. Sin embargo, en el caso valenciano, las expectativas parecen no cumplirse. Las encuestas más recientes (CIS, 1996) muestran que los valencianos se sienten más españoles que los encuestados en cualquiera otra región con lengua propia, se sienten más orgullosos de ser españoles, muestran una mayor preferencia por un Estado unitario y han desarrollado un sentimiento de «identidad dual» (española y valenciana) más fuerte que en cualquier otra región. De hecho, Linz (1973: 84) ya se extrañaba del escaso apoyo y la debilidad de la identidad valenciana a comienzos de los años setenta cuando en otras partes de España florecían las identidades colectivas regionales.

Como señala Herranz (1996: 15), la Comunidad Valenciana aparece en el grupo de autonomías que presentan tendencias más españolistas, junto con Castilla-La Mancha, Madrid y Castilla y León. Si repasamos los factores extraídos por López-Aranguren (1995: 47, 54) para explicar la conciencia regional, se comprueba que en la dimensión política (factor que agrupa las preferencias por la organización territorial del Estado y el status de la comunidad como ente político-territorial) la Comunidad Valenciana se encuentra en unos niveles similares a los de aquellas Comunidades con poca o nula tradición autonomista (Murcia, La Rioja, Extremadura o Andalucía), mientras que entre las Comunidades Autónomas con lengua diferente al castellano es la que menor valor otorga a esta característica a la hora de determinar la conciencia nacionalregional.

2 Ver cuadro 2. 


\section{CUADRO 1}

Comparación de las Comunidades Autónomas con lengua propia

\begin{tabular}{|c|c|c|c|c|c|}
\hline & Cataluña & Baleares & Valencia & Galicia & País Vasco \\
\hline Identificación con España (\%) (1) ....... & 24 & 23 & 34 & 13 & 9 \\
\hline 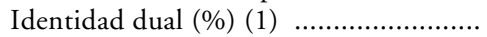 & 36 & 51 & 53 & 44 & 36 \\
\hline Orgullo de ser español (\%) (1) ............. & 78 & 83 & 93 & 87 & 36 \\
\hline A favor de un Estado centralizado (\%) (1) . & 9 & 8 & 17 & 15 & 2 \\
\hline $\begin{array}{l}\text { Población con lengua materna diferente } \\
\text { al castellano }(\%)(1)\end{array}$ & 39 & 47 & 39 & 55 & 16 \\
\hline $\begin{array}{l}\mathrm{VAB}^{*} \text { per capita } 1993 \text { (pts. 1980) (2) ... } \\
\text { Crecimiento medio anual VAB } 1980-\end{array}$ & 1.719 .473 & 2.014 .635 & 1.331 .817 & 1.242 .272 & 1.427 .731 \\
\hline 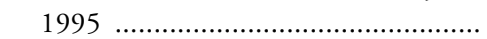 & 3,2 & 3,7 & 2,4 & 2,0 & 1,8 \\
\hline VAB agrícola 1995 (\%) (2) .................. & 1,6 & 1,8 & 3,9 & 9,3 & 1,6 \\
\hline VAB industrial 1995 (\%) (2) ................. & 35,0 & 7,1 & 30,4 & 19,4 & 44,3 \\
\hline 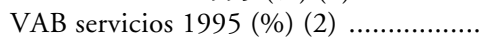 & 44,3 & 75,3 & 42,8 & 39,5 & 35,1 \\
\hline $\begin{array}{l}\text { Media de voto a partidos nacionalistas } \\
\quad(1983-96)(\%)\end{array}$ & 52 & 17 & 9 & 18 & 64 \\
\hline $\begin{array}{l}\text { Peso sobre la población total española } \\
\quad(\%)(3)\end{array}$ & 15,5 & 1,8 & 9,9 & 6,8 & 5,3 \\
\hline
\end{tabular}

* $\mathrm{VAB}=$ Valor Añadido Bruto a coste de los factores o Producto Nacional Bruto (PNB) ${ }^{3}$.

FuENTES: (1) CIS, Estudio 2228, 1996.

(2) D.G. de Análisis y Programación Presupuestaria, Base de Datos Regionales BDMORES, 1998.

(3) INE, Padrón de Población.

Esta situación hace que el valenciano sea un caso desviado. Diferentes autores intentan explicar esta situación anómala. Piqueras (1994) sugiere que la inexistencia de una identidad colectiva valenciana más intensa se debe a la tensión que existe entre una identidad central y unas identidades parciales periféricas cuyo referente colectivo son otras Comunidades Autónomas. Tal tensión, según el autor, impide vertebrar una identidad valenciana dominante. Ariño y Llopis (1995: 4) rechazan el argumento de Piqueras indicando que en otras Comunidades también se puede encontrar esta tensión «y, sin embargo, cuentan con nacionalismos más florecientes e identidades nucleares más implantadas o normalizadas, más hegemónicas. Por lo tanto, esta hipótesis no sirve para explicar lo que hemos denominado la anomalía o excepcionalidad valenciana» ${ }^{4}$. Los autores indican que existe en la sociedad valenciana un con-

3 El Valor Añadido Bruto difiere del PIB en que se descuenta la producción debida a factores propiedad de no nacionales y se añade la producción de fuera del territorio debida a factores propiedad de los nacionales.

${ }_{4}$ Cursivas en el original. 
flicto acerca de la propia identidad que deriva del hecho de que «no hay una identidad central, sino dos que se conciben antagónicamente [catalana y valenciana] y, en ese contexto, la mayoría de los ciudadanos optan por la identidad dominante: el españolismo». A decir verdad, según los datos del CIS (19901993), en esos cuatro años la identidad fundamentalmente valenciana decrece, la identidad fundamentalmente española decrece también, mientras que la identidad dual estricta crece ${ }^{5}$. Esta perspectiva es congruente con la que da Díez Nicolás (1999: 67) tanto para el resto de España como para la Comunidad Valenciana. En definitiva, el fenómeno social al que quizá tenga que prestarse atención es a esa identificación dual que crece en los últimos años y que es la opción de la mayoría de la población valenciana ${ }^{6}$. Este artículo se dedica a esta tarea.

Cuando se utiliza el término identidad colectiva dual se quiere hacer referencia a un doble fenómeno. En primer lugar, se entiende que la identidad colectiva es una representación compartida por los individuos de un territorio acerca de la comunidad de la que se sienten miembros (DiMaggio, 1997: 273). En este sentido, toda identidad colectiva es construida y conflictiva, ya que grupos diferentes pueden tener concepciones distintas acerca de la identidad del colectivo del que se trate ${ }^{7}$. En segundo lugar, las identidades colectivas pueden no ser excluyentes ya que en repetidas ocasiones se ha mostrado cómo las personas son capaces de compatibilizar identidades (por ejemplo, sentirse español y europeo al tiempo) que desde diferentes instancias se pueden presentar como excluyentes Linz (1985). Así pues, la identidad colectiva dual se refiere a ese fenómeno de compatibilización entre marcos de referencia regionalnacional que definen el ámbito de pertenencia de un individuo a una comunidad.

El objeto de este artículo es describir y explicar las bases sociales de la identificación dual en el caso valenciano mediante una serie de variables sociodemográficas y factores construidos a partir del Estudio 2228 sobre conciencia nacional y regional realizado por el Centro de Investigaciones Sociológicas (CIS) entre noviembre y diciembre de 1996. Para ello hemos seguido una línea de actuación triple. En primer lugar, se han extraído, con un análisis factorial, algunas dimensiones que pueden ser relevantes para el estudio de la identidad ${ }^{8}$. En segundo lugar, se ha elaborado un modelo logístico explicativo de la identidad dual en el caso valenciano. Y, finalmente, se ha completado el análisis con

5 Sobre la noción de identidad fundamentalmente española y valenciana y la identidad dual estricta, véase más abajo.

${ }^{6}$ Ver cuadro 2.

Para un análisis interesante acerca de cómo las identidades nacionales son construidas, véase el trabajo de Anderson (1983), y para el caso vasco, véase el texto de Pérez Agote (1984). Sobre la conflictividad de las identidades nacionales, véase el trabajo de Varshney (1993).

8 Siguiendo a López Aranguren (1995), se ha considerado la multidimensionalidad del fenómeno. Por ello hemos realizado un análisis factorial de componentes principales para resumir la información contenida en una parte importante de las preguntas del cuestionario del Estudio 2228 del CIS. La extracción estadística se encuentra expuesta más abajo. 
una regresión lineal para explicar uno de los factores más relevantes que intervienen en el modelo logístico.

\section{LA IDENTIDAD DUAL EN LA COMUNIDAD VALENCIANA}

La variable dependiente que hemos decidido estudiar es la de identificación colectiva. Se corresponde con la pregunta 18 del Estudio 2228 del CIS, que está formulada en los siguientes términos:

¿Con cuál de las siguientes frases se identifica usted en mayor medida?

1. Me siento únicamente español

2. Me siento más español que valenciano

3. Me siento tan español como valenciano

4. Me siento más valenciano que español

5. Me siento únicamente valenciano

El entrevistado/a tenía que escoger una (y sólo una) de las cinco opciones u optar por el «no sabe/no contesta». Se trata de una variable que intenta medir al mismo tiempo la identificación con España y la identificación con la Comunidad Valenciana. Pero no es una variable continua, sino cualitativa. A efectos del análisis se ha realizado una recodificación de las respuestas manteniendo la identidad dual estricta como la respuesta «me siento tan español como valenciano", y unificando las dos primeras respuestas en la categoría «identidad fundamentalmente española»y las dos últimas respuestas en la categoría «identidad fundamentalmente valenciana»". Con esta nueva recodificación las frecuencias de la variable son las que aparecen en el cuadro 2.

Como se puede observar en el cuadro adjunto, de las personas que contestan, un 54,1 por 100 optan por la identidad dual estricta, mientras que el $34,6 \%$ se declaran fundamentalmente españoles y el 11,3 por 100 fundamentalmente valencianos. El objetivo de este trabajo es conocer las bases sociales de la identidad dual.

9 Habría sido posible realizar otro tipo de recodificación manteniendo los dos polos de las respuestas a la pregunta inicial y unificando todas las respuestas que implican cierta identidad dual, tal como hace Moreno (1997) en su estudio. Esta opción es legítima y útil, pero tiene el inconveniente de que en la categoría «identidad dual» se incorporan diferentes grados de «españolismo" y "valencianismo" que contaminan la noción de identidad dual en sentido estricto. En la medida en que las respuestas "me siento más español que valenciano» y «me siento más valenciano que español» implican una cierta predominancia de uno de los polos (identidad española o identidad valenciana), se ha optado por asumirlas en sus polos dominantes y generar una categoría que signifique «identidad dual estricta». 
Dadas las limitaciones que supone trabajar con un cuestionario que no ha sido diseñado por nosotros, se seleccionaron del estudio del CIS aquellas variables que se usaron en otros trabajos que analizan las identidades colectivas (cf. López Aranguren, 1995; Jiménez Blanco et. al., 1977; Herranz, 1996) y se añadieron otras asumiendo que se trataba de variables que, de una manera u otra, podrían tener cierta incidencia en la identificación dual. Al objeto de conocer mejor las características de la población presentamos una tabla resumen basada en una muestra ponderada representativa de la población de la Comunidad Valenciana.

\section{CUADRO 2}

Frecuencias relativas a la identidad

\begin{tabular}{|c|c|c|c|c|c|c|c|}
\hline \multicolumn{4}{|c|}{ Preg 18} & \multicolumn{4}{|c|}{ IDENT3 } \\
\hline & $\begin{array}{l}\text { Frecuen- } \\
\quad \text { cia }\end{array}$ & - $\%$ & $\begin{array}{c}\% \\
\text { válido }\end{array}$ & & $\begin{array}{l}\text { Frecuen- } \\
\text { cia }\end{array}$ & - $\%$ & $\begin{array}{c}\% \\
\text { válido }\end{array}$ \\
\hline 1 & 115 & 19,4 & 19,6 & fundamentalm & & & \\
\hline 2 & 88 & 14,8 & 15,0 & español $1+2$ & 203 & 34,2 & 34,6 \\
\hline 3 & 317 & 53,5 & 54,1 & dual 3 & 317 & 53,5 & 54,1 \\
\hline 4 & 58 & 9,8 & 9,9 & fundamentalm & & & \\
\hline 5 & 8 & 1,3 & 1,4 & valenciano $4+5$ & 66 & 11,1 & 11,3 \\
\hline Total & 586 & 98,8 & 100,0 & Total & 586 & 98,8 & 100,0 \\
\hline Missing & 7 & 1,2 & & Missing & 7 & 1,2 & \\
\hline Total & 7 & 1,2 & & Total & 7 & 1,2 & \\
\hline TOTAL & & 593 & 100,0 & TOTAL & 5931 & 100,0 & \\
\hline
\end{tabular}




\begin{tabular}{cccccccc} 
& $\begin{array}{c}\text { Fundamen- } \\
\text { talmente }\end{array}$ & \multicolumn{5}{c}{$\begin{array}{c}\text { Fundamen- } \\
\text { talmente }\end{array}$} \\
Eariable & española & Dual & valenciana & & & \\
(1) & estricta & (2) & Total & (1+2) & Si & Total \\
\hline
\end{tabular}

Sexo

Hombre

38,1

48,8

$13,2 \quad 100(281)$

51,2

$48,8 \quad 100(281)$

Mujer

31,5

59,0

$9,5 \quad 100(305)$

41,0

$59,0 \quad 100(305)$

\section{Edad}

Joven

$$
26,1
$$

55,7

$18,2 \quad 100(88) \quad 44,3$

$55,7 \quad 100(88)$

Maduro-joven ... 37,1

50,0

12,9

$100(124) \quad 50,0$

$50,0 \quad 100(124)$

Maduro

36,5

54,1

$9,4 \quad 100(266)$

45,9

$54,1 \quad 100(266)$

Mayor

$34,3 \quad 57,4$

$8,3 \quad 100(108)$

42,6

$57,4 \quad 100(108)$

\section{Nacimiento}

Comunidad

25,8

60,1

$14,1 \quad 100(434)$

39,9

$60,1 \quad 100(434)$

Inmigrantes

$59,9 \quad 36,8$

$3,3 \quad 100(152)$

63,2

$36,8 \quad 100(152)$

\section{Hábitat}

Rural

24,8

66,2

$9,0 \quad 100(133)$

33,8

66,2 $100(133)$

Semirural

34,3

54,0

$11,7 \quad 100(248)$

46,0

$54,0 \quad 100(248)$

Urbano

$41,5 \quad 46,3$

$12,2 \quad 100(215)$

53,7

$47,3 \quad 100(215)$

\section{Ocupación*}
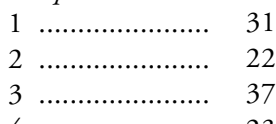

31,3

56,3

$12,5 \quad 100(32)$

43,8

56,3

$100(32)$

61,1

$16,7 \quad 100(18)$

38,9

$61,1 \quad 100(18)$

$37,3 \quad 49,0$

$13,7 \quad 100(51)$

51,0

49,0 $100(51)$

67,9

$8,3 \quad 100(84)$

32,1

$67,9 \quad 100(84)$

53,9

9 ,

$100(241)$

46,1

$53,9100(241)$

6

54,1

14 ,

45,9

$54,1 \quad 100(156)$

\section{Lengua}

Castellano

50,0

42,8

$7,2 \quad 100(318)$

57,2

$42,8 \quad 100(318)$

Valenciano

14,7

68,4

$16,9 \quad 100(231)$

31,6

$68,4 \quad 100(231)$

Bilingüe

61,5

$$
11,
$$

$100(26)$

38,5

$61,5 \quad 100(26)$

\section{Educación ${ }^{* *}$}

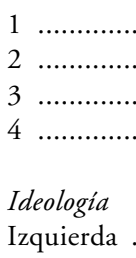

$$
43,2
$$

49,5

$$
7,4
$$

$100(95)$

50,5

49,5 $100(95)$

59,2

$8,5 \quad 100(306)$

40,8

$59,2 \quad 100(306)$

51,6

14,

41,3

$23,8 \quad 100(63) \quad 58,7$

$51,6 \quad 100(122)$

$41,3 \quad 100(63)$

$$
25,0
$$

50,0

25,

53,3

Centro-der.

57,6

12,7

$100(36)$

50,0

$50,0 \quad 100(36)$

Derecha

29,7

44,4

11 ,

$100(383)$

46,7

$53,3 \quad 100(383)$

$57,6 \quad 100(158)$

$44,4 \quad 100$ (9) 


\begin{tabular}{|c|c|c|c|c|c|c|c|}
\hline Variable & $\begin{array}{l}\text { Fundamen- } \\
\text { talmente } \\
\text { española } \\
\text { (1) }\end{array}$ & $\begin{array}{c}\text { Dual } \\
\text { estricta }\end{array}$ & $\begin{array}{l}\text { Fundamen- } \\
\text { talmente } \\
\text { valenciana } \\
\text { (2) }\end{array}$ & Total & $\begin{array}{c}N o \\
(1+2)\end{array}$ & Si & Total \\
\hline \multicolumn{8}{|l|}{$\begin{array}{l}\text { Identificación }{ }^{* * *} \\
\text { Provincial } \\
\text { fuerte }\end{array}$} \\
\hline No ........................ & 53,2 & 34,0 & 12,8 & $100(94)$ & 66,0 & 34,0 & $100(94)$ \\
\hline $\begin{array}{l}\text { Sí .......................... } \\
\text { Comunidad } \\
\text { fuerte }\end{array}$ & 31,1 & 57,9 & 11,0 & $100(492)$ & 42,1 & 57,9 & $100(492)$ \\
\hline No ....................... & 56,8 & 33,7 & 9,5 & $100(95)$ & 66,3 & 33,7 & $100(95)$ \\
\hline $\begin{array}{c}\text { Sí ...................... } \\
\text { España fuerte }\end{array}$ & 30,3 & 58,0 & 11,6 & $100(491)$ & 42,0 & 58,0 & $100(491)$ \\
\hline No $\ldots . . . . . . . . . . . . . .$. & 34,1 & 36,5 & 29,4 & $100(85)$ & 63,5 & 36,5 & $100(85)$ \\
\hline Sí . ...................... & 34,7 & 57,1 & 8,2 & $100(501)$ & 42,9 & 57,1 & $100(501)$ \\
\hline
\end{tabular}

* 1 = directivos, propietarios, gerentes; 2 = jefes, mandos intermedios, capataces; 3 = profesionales y técnicos; 4 = trabajadores en la agricultura; 5 = trabajadores de la industria y la construcción; 6 = trabajadores del sector servicios.

** 1 = analfabetos y primaria incompleta; 2 = estudios primarios; 3 = estudios secundarios $o$ medios; 4 = estudios superiores.

*** La identificación fuerte se refiere a los valores 8, 9 y 10 de las escalas de identificación con la provincia, la Comunidad Autónoma y España. Los valores 1, 2 y 3 corresponden a una identificación débil, y los valores 4, 5, 6 y 7 a una identificación media.

La identidad dual estricta está más presente entre las mujeres que entre los hombres, aunque éstos se declaran con más asiduidad fundamentalmente valencianos que las mujeres. En términos generales existen pocas diferencias entre grupos de edad en lo que hace referencia a la identidad dual estricta, aunque son las personas de la categoría «maduro-joven» (entre 25 y 34 años) las que presentan una tasa más baja (50 por 100). Curiosamente, los nacidos en la Comunidad Valenciana presentan un porcentaje de identidad dual estricta superior al de los inmigrantes. Los valencianos/as de nacimiento optan más por la identidad fundamentalmente española que por la valenciana, aunque con menor intensidad que los inmigrantes. Si se tiene en cuenta que la inmigración tiende a asentarse en núcleos urbanos, no parece raro que las tasas más elevadas de identidad fundamentalmente española se encuentren en hábitats urbanos. Pero lo mismo ocurre con la identidad fundamentalmente valenciana. Con los datos de que se dispone se observa que la urbanización va pareja a un descenso de la identidad dual estricta. Éste es un aspecto que convendrá explorar en análisis posteriores. En referencia a las profesiones, se tiene que señalar que en casi todas ellas más de la mitad de los encuestados/as optan por la identidad dual. Adicionalmente, destacan dos grupos. Los jefes, mandos intermedios y capataces, y los trabajadores del sector agrícola presentan el porcentaje 
más bajo de identidad fundamentalmente española y los más altos de identidad dual estricta.

Respecto de la lengua del entrevistado el panorama es un poco más complejo. Mientras los/as castellanohablantes se decantan fundamentalmente por la identidad española (50 por 100$)$ o por la dual $(42,8$ por 100$)$, los/as valencianohablantes optan mayoritariamente por la identidad dual $(68,4$ por 100$)$. Entre éstos, la opción «identidad fundamentalmente valenciana» es sensiblemente superior a la española (16,9 frente a 14,7 por 100$)$. Los/as bilingües también optan mayoritariamente por la identidad dual (61,5 por 100), seguida por la identidad fundamentalmente española (26,9 por 100). Habrá que explorar un poco más las relaciones entre lengua e identidad en fases posteriores tomando como ejemplo el caso valenciano.

Si se observa la variable educación se puede concluir que a medida que aumenta el nivel educativo se incrementa la frecuencia de identidad fundamentalmente valenciana. Conviene retener este dato para posteriores análisis. Las personas que han alcanzado un nivel educativo superior presentan las menores tasas de identidad dual y las más elevadas de identidad valenciana. Por contra, las personas con estudios primarios tienen las menores frecuencias de identidad fundamentalmente española, las más altas de identidad dual y las más bajas de identidad valenciana. Con los datos de que se dispone no se observa una clara correlación entre la ideología y la identidad colectiva, aunque tendremos oportunidad de valorar esta relación con análisis estadísticos más avanzados. Lo que sí se observa es que las tasas más elevadas de identidad fundamentalmente valenciana y las más bajas de identidad fundamentalmente española se encuentran en la izquierda. El centro-izquierda presenta las frecuencias más bajas de identidad valenciana y las más altas (después de los ciudadanos que se declaran de derechas) de identidad española. Por contra, las personas que se declaran de centro-derecha son las que con más frecuencia optan por la identidad dual.

No existen grandes diferencias respecto de la opción por la identidad entre las variables de identificación provincial y con la Comunidad Valenciana. Las personas que tienen una identificación fuerte con estos referentes territoriales tienden a optar mayoritariamente por la identidad dual, mientras que las que presentan una identificación débil o media suelen optar también mayoritariamente por la identidad fundamentalmente española. Una situación distinta ocurre con las personas que se identifican fuertemente con España. En este caso los entrevistados/as optan mayoritariamente por la identidad dual y, con menor frecuencia, la identidad fundamentalmente española. Por contra, las personas que tienen una identificación débil o media con España suelen optar con mayor frecuencia, que las otras por la identidad fundamentalmente valenciana, mientras que reparten casi por igual sus preferencias por la identidad dual o fundamentalmente española.

El análisis de las frecuencias nos ofrece una panorámica de la distribución de la población en función de una serie de variables. Se puede ir un poco más 
allá y recurrir a diferentes técnicas estadísticas para intentar averigüar cuáles son los determinantes de la identidad dual. Para guiar esta fase de la investigación se elaboró un conjunto de hipótesis en base tanto al análisis de frecuencias anterior como a las aportaciones de autores diferentes. Son las siguientes:

1. Primordialismo a: nacimiento. (1) Siguiendo la tesis primordialista (Geertz, 1973), se asumió que los nacidos en el territorio de la Comunidad Valenciana pueden tender a presentar una identidad colectiva fundamentalmente valenciana en detrimento de la identidad dual y la fundamentalmente española. Por contra, los nacidos fuera de la Comunidad pero residentes (es decir, los/as inmigrantes), ante la alternativa de escoger entre la identidad española o la valenciana, pueden optar con mayor frecuencia por identificarse o bien con la primera o de manera dual. En consecuencia, se espera un impacto negativo de la variable nacimiento sobre la identidad dual. (2) Existe, sin embargo, una alternativa a esta hipótesis. De acuerdo con Linz (1985), la característica fundamental de las identidades colectivas en España es que dejan de lado su carácter primordialista (medido como el producto del nacimiento, los antepasados y la lengua) para hacerse más integradoras centrándose en el criterio de adscripción territorial. Si éste es el caso, y teniendo en cuenta que desde el punto de vista territorial ser miembro de una Comunidad Autónoma no es incompatible con sentirse parte de la comunidad española, es previsible que la variable nacimiento tenga un impacto positivo sobre la identidad dual.

2. Primordialismo b: lengua. Desde Herder, la lengua materna se ha venido considerando como un señalizador cultural que vehicula la identidad colectiva (vide Tejerina, 1992: 53; López Aranguren, 1995: 67; Moya, 1984: 20), aunque en algunos casos se indica que tal señalizador adquiere significado en situaciones de conflicto lingüístico. Nadie duda que en la Comunidad Valenciana tal conflicto existe ${ }^{10}$. En consecuencia, se pensó que aquellos/as que tienen como lengua materna el valenciano tendrán menos probabilidades de presentar una identidad dual o fundamentalmente española que los/as bilingües o castellanohablantes. Por contra, dada la estructura lingüística de la Comunidad Valenciana ${ }^{11}$ y las tres dimensiones de la lengua (uso, prestigio, política) que indican Pérez-Agote y Tejerina (1990), los/as que tienen como lengua materna el castellano no necesariamente tendrán más probabilidades de presentar una identidad fundamentalmente española. Alternativamente, una lectura de los

${ }^{10}$ Véanse los trabajos de Ninyoles (1969) y, muy especialmente, el de Sanchis Guarner (1994) para un análisis del conflicto lingüístico valenciano.

11 Recordemos que en la Comunidad Valenciana existen dos áreas lingüísticas claramente delimitadas que son el producto de la conquista (y nacimiento) del antiguo Reino de Valencia. Las áreas lingüísticas se corresponden grosso modo con las áreas territoriales en que se instalaron los contingentes poblacionales (castellanos, navarros, catalanes, mallorquines) que conquistaron el reino. Es decir, desde su fundación, la Comunidad Valenciana ha acogido tanto el castellano como el valenciano como lenguas propias. 
trabajos de Hobsbawm (1990: 59-63, 134), Anderson (1983: 74), Linz (1975: 370) y Ninyoles (1971: 153 y ss.) indica que la lengua materna no es necesariamente un vehiculador de la identidad colectiva, sugiriendo así que otros factores pueden intervenir en la conformación de la identidad. Por otra parte, estos autores sugieren que la lengua materna no es obstáculo para compatibilizar identidades colectivas que se expresan en lenguas diferentes. En consecuencia, desde este planteamiento, se espera que cuando la variable «lengua materna" adquiera el valor "no castellano" tenga un efecto positivo en la identidad dual.

3. Género. No se estableció ninguna hipótesis de partida puesto que no se considera que la identidad dual sea función del género. En consecuencia, se espera que ésta no sea una variable significativa respecto de la identidad dual. No obstante, se mantiene en el conjunto de variables seleccionadas para observar su comportamiento.

4. Hábitat. Se partió del presupuesto que los hábitats urbanos, por su mezcla de referentes colectivos, pueden producir una mayor tendencia a la identidad dual, mientras que los hábitats rurales, dadas sus características homogeneizadoras, pueden fomentar más las tendencias hacia los polos identitarios.

5. Edad. Es probable que aquellas personas que hayan estado socializadas en un Estado unitario tengan más probabilidades de presentar identidades polares que aquellas personas que han sido socializadas en un Estado que se reconoce plural (como el Estado de las Autonomías), quienes por esta razón es más probable que presenten identidades duales. En consecuencia, cabe esperar entre los/as jóvenes y maduro-jóvenes una mayor tendencia a la identidad dual que entre los más mayores.

6. Educación. De acuerdo con algunos autores (Mollà y Mira, 1986; Sanchis Guarner, 1994: 195-202; Linz, 1973: 84), el incipiente movimiento nacionalista en la Comunidad Valenciana durante y después de la transición política está liderado (y compuesto) por personas procedentes de la universi$\mathrm{dad}$, intelectuales, la intelligentzia. Tal afirmación encaja con los modelos nacionalistas clásicos estudiados por Hroch (1985). De la misma manera, tanto Hechter (1989) como Anderson (1983) y Gellner (1983) ponen de relieve que la conciencia nacionalista es algo que se da con más frecuencia entre las capas ilustradas de la sociedad (intelectuales, maestros, clérigos). Si esta afirmación es cierta, es de suponer que será en estas capas donde menos identificación dual habrá. Es decir, que cuanto mayor sea el nivel educativo, menos probabilidades de encontrar la identidad dual.

7. Ocupación. La literatura de la teoría de la elección racional (Rogowski, 1985; Hechter, 1989) indica que las profesiones relacionadas con los servicios (trabajadores y técnicos de este sector) suelen presentar una mayor frecuencia de identidad nacionalista que otros trabajadores/as. En consecuencia, es bastante probable que cuando la variable ocupación adopte los valores de estos segmentos profesionales se registre un impacto negativo en la variable identidad dual. 
8. Ideología política. Se pensó que la ideología podría tener un impacto claro en la identidad de los individuos. Debido a la historia política reciente (cf. Mollà y Mira, 1986), en la que las reivindicaciones nacionalistas —que implican una afirmación de la identidad colectiva valenciana- han ido aparejadas con una postura política de izquierdas, se pensó que las personas que adoptan esta ideología tienen más probabilidades de presentar identidad valenciana que las que se declaran de derechas y, en consecuencia, el impacto sobre la identidad dual cuando la variable ideología política adquiere valores de izquierda será menor.

9. Identificación provincial. Es un lugar común indicar que para el caso valenciano la identidad provincial supone una barrera para la vertebración de una identidad colectiva netamente valenciana (Fuster, 1962; Mira, 1984). Ello sugiere que una fuerte identificación provincial puede derivar hacia una identidad dual o fundamentalmente española. En consecuencia, se espera que esta variable tenga un efecto positivo sobre la identidad dual.

10. Identificación con la Comunidad Valenciana. Se piensa que una identificación fuerte con la Comunidad Valenciana puede derivar en una mayor presencia de identidad valenciana frente a la identidad dual y española. En consecuencia, se espera un impacto negativo de esta variable en la identidad dual.

11. Identificación con España. Se piensa que una identificación fuerte con la idea de España puede derivar en una identidad fundamentalmente española, reduciendo las posibilidades de que emerja una identidad dual que combine tanto la valenciana con la española. En consecuencia, se espera un impacto negativo de esta variable en la dependiente.

Con la finalidad de poder introducir variables diferentes a las sociodemográficas, y siguiendo el ejemplo de López Aranguren (1995), realizamos un análisis factorial de componentes principales que ayudara a resumir la información sobre la conciencia regional y nacional de los/as valencianos recogida en una parte importante de los ítems de las preguntas de la encuesta. La elección de los ítems se realizó después de un análisis exhaustivo de la matriz de correlaciones del conjunto de preguntas consideradas, todas ellas al menos ordinales y reordenadas de forma que el sentido fuera creciente. Los NS/NC fueron considerados como valores perdidos. El resultado de la elección de ítems fue el siguiente ${ }^{12}$ :

12 A partir de estas preguntas se aplicó un análisis factorial de componentes principales, ya que el test de esfericidad de Bartlett es significativo y la medida de adecuación de Kaiser-MeyerOlkin (KMO) nos daba un valor de 0,79, que el propio Kaiser hubiera calificado de meritorio. Con una rotación ortogonal por el criterio varimax con una normalización Kaiser, después de 6 iteraciones, se obtuvieron 5 factores, que explicaban el 58,9 por 100 de la varianza. 
PP20 Orgullo de ser español. 1=Nada orgulloso; 4=Muy orgulloso.

PP21 Emoción ante la bandera o el himno español. 1=Nada especial; 4=Mucha emoción.

PP22 Emoción ante medalla olímpica de español. 1=Nada especial; 4=Mucha emoción.

PP2301 España no existe, lo que existe es el Estado español. 1=Muy en desacuerdo; 5=Muy de acuerdo.

PP2302 La historia de España es muy admirable. Ídem.

PP2303 España es una realidad profunda. Ídem.

PP2304 España nunca ha sido una nación, es una suma de naciones. Ídem.

PP2305 Lo mejor que podía pasar es que España se divida. Ídem.

PP2306 La comunidad de la que me siento miembro es España. Ídem.

PP2307 España unida tiene ventajas para todos. Ídem.

PP27 Organización territorial del Estado preferida. 1=Unitario; 2=Autonómico; $3=$ Federal; 4=Confederal.

PP28 Participación preferida de la Comunidad Autónoma en el Estado. 1=Región; 2=CC.AA.; Estado federado; 4=Estado confederado.

PP3901 Las CC.AA. acercan los asuntos al ciudadano. 1=Muy en desacuerdo; 4=Muy de acuerdo.

PP3903 Las CC.AA. mejoran la convivencia. Ídem.

PP40 Creación y desarrollo de las CC.AA. 1=Negativo; 3=Positivo.

PP41 Funcionamiento del Estado de las Autonomías. 1=Muy mal; 5=Muy bien.

PP42 Experiencia de gobierno autónomo. 1=Muy perjudicial; 5=Muy beneficiosa.

PP5401 En elecciones autonómicas es mejor votar a un partido propio. 1=Muy en desacuerdo; 5=Muy de acuerdo.

PP5403 En elecciones autonómicas es mejor votar a un partido diferente al del gobierno central. Ídem.

Tenemos un primer componente principal que explica el 14,3 por 100 de la varianza y que, por estar explicado por las preguntas PP41, PP40, PP42, PP3901 y PP3903, hemos denominado Valoración del Estado de las Autonomías. Un segundo factor que explica el 13,97 por 100 de la varianza y que, por estar explicado por las preguntas PP2303, PP2302, PP2307, PP2306, PP2304 y PP2305, hemos denominado Consideración de la unidad nacional española. En tercer lugar, extraemos un factor explicado por las preguntas PP21, PP22, PP20 y PP2301, que da cuenta del 12,42 por 100 de la varianza y hemos denominado Adhesión afectiva a España. En cuarto lugar, se puede extraer un componente que explica el 10,25 por 100 de la varianza y que es explicado por las preguntas PP27 y PP28, por ello lo denominamos Centralismo estatal. Y, finalmente, obtenemos un factor que da cuenta de un 7,98 por 100 de la varianza y es explicado por las preguntas PP5403 y PP5401, por lo que lo hemos denominado Autonomía politica. 


\section{Rotated Component Matrix ${ }^{\mathrm{a}}$}

\begin{tabular}{|c|c|c|c|c|c|}
\hline & \multicolumn{5}{|c|}{ Componentes } \\
\hline & 1 & 2 & 3 & 4 & 5 \\
\hline PP41 & 0,796 & & & & \\
\hline  & 0,741 & & & $-0,339$ & \\
\hline ........................... & 0,722 & & & & \\
\hline 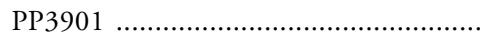 & 0,665 & & & & \\
\hline 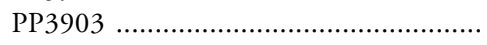 & 0,647 & & & & \\
\hline PP2303 & & 0,803 & & & \\
\hline 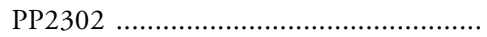 & & 0,689 & 0,250 & & 0,217 \\
\hline 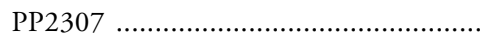 & & 0,683 & & 0,219 & \\
\hline 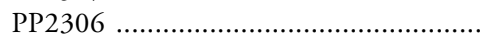 & & 0,563 & & 0,329 & \\
\hline 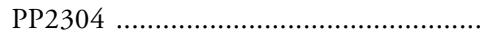 & & $-0,443$ & $-0,285$ & & \\
\hline 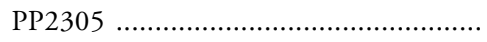 & & $-0,425$ & & $-0,209$ & 0,374 \\
\hline PP21 & & & 0,859 & & \\
\hline 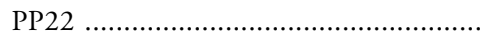 & & & 0,857 & & \\
\hline PP20 & & 0,342 & 0,604 & & $-0,205$ \\
\hline 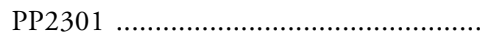 & & $-0,335$ & $-0,464$ & & \\
\hline PР27 & $-0,216$ & & & 0,877 & \\
\hline 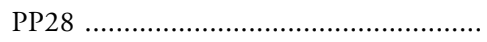 & $-0,256$ & & & 0,861 & \\
\hline 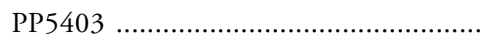 & & & & & 0,795 \\
\hline  & & & & & 0,746 \\
\hline
\end{tabular}

Extraction Method: Principal Component Analysis.

Rotation Method: Varimax with Kaiser Normalization.

a Rotation converged in 6 iterations.

Estos cinco factores pueden tener una incidencia en la identidad de los entrevistados/as. De su consideración se derivan las siguientes hipótesis finales que interesa contrastar:

12. Factor 1 (valoración del Estado de las Autonomías). Se piensa que una valoración positiva del Estado de las Autonomías puede tener alguna relación con la identidad dual en la medida en que ni niega la existencia de España ni afirma la identidad excluyente valenciana. En consecuencia, se espera un impacto positivo de esta variable (factor) o cuando menos un efecto ambiguo.

13. Factor 2 (consideración de la unidad nacional española). A diferencia del factor 1, en este caso la consideración positiva de la unidad nacional de España puede estar relacionada con una identidad española que excluya otras posibilidades como la identidad dual. Sin embargo, puede justificarse también que la concepción de la unidad nacional española no necesariamente excluye la presencia de identidades duales. En consecuencia, el impacto de esta variable en la dependiente puede ser ambiguo. 
14. Factor 3 (adhesión afectiva a España). Las mismas consideraciones realizadas para el factor 2 sirven para éste.

15. Factor 4 (centralismo estatal $)^{13}$. Es previsible que aquellas personas que optan por un modelo de Estado centralizado (esto es, sin autonomías) presenten una identidad fundamentalmente española, aunque ello no excluye la presencia de identidad dual. Por tanto, el impacto de este factor puede ser ambiguo.

16. Factor 5 (autonomía política). Este factor recoge la preferencia por el voto a partidos de ámbito autonómico en elecciones autonómicas. Asumiendo que tal voto puede ser indicador de una tendencia hacia la identidad fundamentalmente valenciana, es previsible que el impacto de esta variable sobre la identidad dual sea negativo. Sin embargo, la hipótesis alternativa también puede ser cierta. En la medida en que el deseo por una mayor presencia de partidos autonómicos en el escenario político no va necesariamente aparejado a una identidad polar. Puede ser que el efecto de este factor en la identidad dual sea positivo.

\section{UN MODELO EXPLICATIVO DE LA IDENTIDAD DUAL}

Para saber en qué medida las 16 variables explican la presencia de identidad dual se procedió a averiguar si estas variables están asociadas a la variable dependiente. Se ejecutó una correlación bivariada y se sometió el resultado de la correlación a un test de significatividad. Se escogió una significación del 0,1 .

En esta primera aproximación se puede observar que ni la edad, ni la ocupación, ni la ideología, ni la educación, ni los factores 4 y 5 parecen presentar asociación significativa alguna con la variable identidad colectiva dual, con lo que se refutan las hipótesis 5, 6, 7, 8, 15 y 16 en línea con algunas de las tesis avanzadas por Jiménez Blanco et al. (1977: 48).

Con el conjunto de variables que presentan una correlación significativa con la identidad dual se trata ahora de obtener un modelo que permita explicar la variable dependiente. La técnica estadística de la regresión parece la más adecuada. Como la variable dependiente es cualitativa politómica se debe aplicar un tipo de regresión logística (Guillén, 1992; Jovell, 1995). A tal efecto, y como la categoría que interesa analizar es la de «identidad dual», se creó una variable ficticia dicotómica (DUMID3) a partir de la variable inicial con valores 1 (para los/as que presenten identidad dual) y 0 (para el resto, es decir, los que presentan identidad fundamentalmente valenciana o fundamentalmente española). Con esta variable dicotómica se puede realizar un análisis de regresión logística que nos permitirá conocer

13 Nótese que en los factores 2, 3 y 4 se asume que puede existir un sustrato de identidad fundamentalmetne española compatible con la identidad dual. 


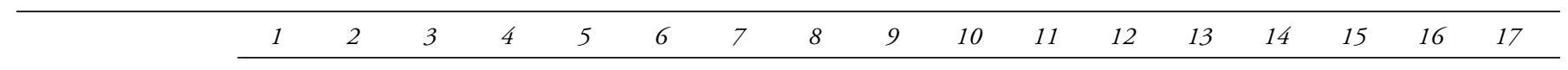

1. Dumid3*

1

2. Nacimiento ...... $0,205 \quad 1$

3. Hábitat ........... $-0,146-0,179 \quad 1$

4. Lengua $\ldots \ldots \ldots \ldots . . . .0,224 \quad 0,399-0,200 \quad 1$

5. Ocupación ....... $-0,160-0,101-0,015-0,123 \quad 1$

6. Sexo …............ $0,103-0,003-0,004 \quad 0,073-0,018 \quad 1$

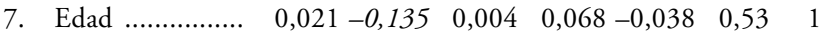

8. Educación ........ $-0,059 \quad 0,102 \quad 0,200 \quad 0,007-0,150-0,040-0,409 \quad 1$

9. Ideología …...... $0,031 \quad 0,070-0,101 \quad 0,181-0,063 \quad 0,077 \quad 0,047-0,050 \quad 1$

10. Factor $1 \ldots \ldots \ldots . . .0,202 \quad 0,015-0,120 \quad 0,031 \quad 0,012 \quad 0,049-0,098-0,027-0,049 \quad 1$

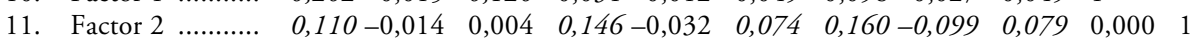

12. Factor 3 .......... $0,091 \quad 0,005-0,001-0,045-0,020 \quad 0,100 \quad 0,120 \quad 0,208-0,115 \quad 0,000 \quad 0,000 \quad 1$

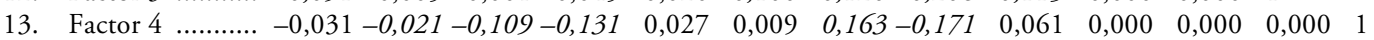

14. Factor 5 .......... -0,018-0,093-0,015-0,041 $0,072-0,002 \quad 0,010-0,101-0,001 \quad 0,000 \quad 0,000 \quad 0,000 \quad 0,000 \quad 1$

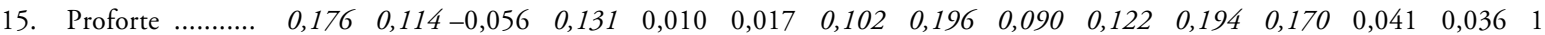



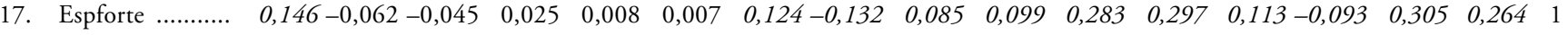

* En cursiva están los coeficientes de correlación que son significativos al 0,1. 
el efecto de las variables independientes (nacimiento, lengua, etc.) en la dependiente (identidad dual). El modelo que se persigue tiene la siguiente forma:

$$
\mathrm{Y}=\mathrm{a}+\mathrm{b}_{1} \mathrm{x}_{1}+\mathrm{b}_{2} \mathrm{x}_{2}+\ldots+\mathrm{b}_{\mathrm{n}} \mathrm{x}_{\mathrm{n}}
$$

donde $\mathrm{Y}$ es la variable dependiente (identidad dual, con dos valores: 1 = sí, $0=$ no), «a» es el término constante, $b_{1 \ldots n}$ son los coeficientes que indican tanto la dirección (con el signo) como la intensidad (valor del coeficiente) del efecto de la variable independiente en la dependiente, $\mathrm{y} \mathrm{x}_{1 \ldots . \mathrm{n}}$ son las variables independientes. Las variables independientes son todas cualitativas menos los factores, que son variables continuas ${ }^{14}$. El modelo de regresión obtenido se presenta en el cuadro siguiente.

\section{CUADRO 3}

Modelo de regresión

\begin{tabular}{|c|c|c|c|c|c|c|c|}
\hline $\begin{array}{l}-2 \text { Log Likelihood } \\
\text { Goodness of Fit } \\
\text { Cox \& Snell }-R^{\wedge} 2 \\
\text { Nagelkerke }-R^{\wedge} 2\end{array}$ & & $\begin{array}{c}714,306 \\
585,091 \\
0,148 \\
0,198\end{array}$ & Model & $\begin{array}{c}\text { Chi-Square } \\
94,126\end{array}$ & & $d f 12$ & $\begin{array}{l}\text { ignificance } \\
0,0000\end{array}$ \\
\hline Variable & $B$ & S.E. & Wald & $d f$ & Sig & $R$ & $\operatorname{Exp}(B)$ \\
\hline Nacimiento ...... & 0,7634 & 0,2350 & 10,5518 & 1 & 0,0012 & 0,1029 & 2,1455 \\
\hline Sexo ...................... & 0,3413 & 0,1823 & 3,5053 & 1 & 0,0612 & 0,0432 & 1,4068 \\
\hline Rural ................ & 0,1488 & 0,2477 & 0,3608 & 1 & 0,5481 & 0,0000 & 1,1604 \\
\hline Urbana ............... & $-0,2166$ & 0,2083 & 1,0808 & 1 & 0,2985 & 0,0000 & 0,8053 \\
\hline Castellano ......... & $-0,9005$ & 0,3867 & 5,4227 & 1 & 0,0199 & $-0,0651$ & 0,4064 \\
\hline Valenciano ......... & $-0,4042$ & 0,4092 & 0,9758 & 1 & 0,3232 & 0,0000 & 0,6675 \\
\hline Proforte ................ & 0,3083 & 0,3789 & 0,6619 & 1 & 0,4159 & 0,0000 & 1,3611 \\
\hline Comforte ........... & 0,2531 & 0,3743 & 0,4574 & 1 & 0,4988 & 0,0000 & 1,2880 \\
\hline Espforte .............. & 0,5247 & 0,2882 & 3,3145 & 1 & 0,0687 & 0,0403 & 1,6899 \\
\hline FAC1 $\ldots \ldots \ldots \ldots \ldots$ & 0,4066 & 0,0947 & 18,4369 & 1 & 0,0000 & 0,1426 & 1,5017 \\
\hline FAC2 …............ & 0,1304 & 0,0968 & 1,8142 & 1 & 0,1780 & 0,0000 & 1,1393 \\
\hline FAC3 ….............. & 0,1502 & 0,0979 & 2,3539 & 1 & 0,1250 & 0,0209 & 1,1621 \\
\hline Constant ........... & $-0,8025$ & 0,5251 & 2,3358 & 1 & 0,1264 & & \\
\hline
\end{tabular}

\section{DISCUSIÓN DE LOS RESULTADOS}

Con este modelo podemos empezar a operar y extraer conclusiones. Vemos que las variables nacimiento, género, lengua materna castellana, identificación

${ }^{14}$ A efectos del modelo de regresión y en las variables politómicas con más de dos categorías se ha dejado fuera del modelo una categoría que será la que se use de contraste en los análisis posteriores. 
fuerte con España y el factor 1 (percepción de las autonomías) son significativas a un nivel del 0,1 , siendo la lengua materna castellana la que tiene un mayor impacto (pero negativo) en la variable dependiente. Para examinar algunas de las hipótesis planteadas más arriba se tiene que operar con los coeficientes (B) y con las medias de las variables para mantenerlas constantes ${ }^{15}$.

Nacimiento. Con la ecuación de regresión podemos averiguar cuál es la probabilidad estimada de que la variable «identidad dual» esté presente en función de los valores ( 1 ó 0$)$ de la variable «nacimiento».

$$
\mathrm{P}(\mathrm{Y}=1 \mid \text { naix }=1)=\exp \mathrm{z} /(1+\exp \mathrm{z})
$$

donde $\mathrm{z}=0,1661-$ (naix [media] ${ }^{*}$ bnaix $)+(1 *$ bnaix $)$.

Intercalando los datos de que disponemos resulta que

$$
z=0,1661-0,5649+0,7634=0,3652
$$

Sustituyendo este resultado en la ecuación de la probabilidad resulta que

$$
\mathrm{P}(\mathrm{Y}=1 \mid \text { naix }=1)=0,59
$$

Este dato indica que los que han nacido en la Comunidad Valenciana (nacimiento $=1$ ) tienen un 59 por 100 de probabilidades de manifestar la identidad dual si se mantienen las otras variables constantes. Es decir, una persona escogida al azar que haya nacido en la Comunidad Valenciana tiene un 59 por 100 de probabilidades de presentar una identidad dual. Por contra, siguiendo los mismos pasos para el caso de los inmigrantes (nacimiento $=0$ ) resulta que éstos tienen una probabilidad de manifestar la identidad dual del 40 por 100. En consecuencia, es un 20 por 100 más probable que los nacidos en la Comunidad Valenciana tengan una identidad dual frente a los que no han nacido en este territorio. Por tanto, para el caso valenciano, se tiene que

${ }^{15}$ La fórmula para encontrar este efecto es la siguiente:

$$
\text { Probabilidad }(Y=1 \mid \text { naix }=1)=\exp z /(1+\operatorname{expz})
$$

donde $\mathrm{z}=\left[\sum\left(\operatorname{media~}_{1 \ldots \mathrm{n}} * \mathrm{~b}_{1 \ldots \mathrm{n}}\right)\right]-\left[\operatorname{media}_{\text {naix }} * \mathrm{~b}_{\text {naix }}\right]+\left[1 * \mathrm{~b}_{\text {naix }}\right]$

De manera similar,

$$
\text { Probabilidad }(\mathrm{Y}=1 \mid \text { naix }=0)=\exp \mathrm{z} /(1+\operatorname{expz})
$$

donde $\mathrm{z}=\left[\sum\left(\operatorname{media~}_{1 \ldots \mathrm{n}} * \mathrm{~b}_{1 \ldots \mathrm{n}}\right)\right]-\left[\operatorname{media~}_{\text {naix }} * \mathrm{~b}_{\text {naix }}\right]+\left[0 * \mathrm{~b}_{\text {naix }}\right]$

Es decir, para mantener constantes las variables se inserta la media de cada variable en la ecuación del modelo. El sumatorio de los productos de las medias de cada variable por su coeficiente correspondiente es 0,1661 . 
rechazar la hipótesis primordialista y afirmar que el nacimiento en el territorio de la Comunidad Valenciana aumenta las probabilidades de presentar una identidad dual en relación con el factor migratorio.

Género. En la hipótesis 2 se indica que no esperamos que esta variable sea significativa en la presencia de identidad dual. Sin embargo, con los datos de que disponemos, el sexo del entrevistado/a aparece como un elemento importante en la conciencia colectiva. Habrá que explorar más en las razones teóricas de tal relación. Por el momento, sólo podemos constatar que si se mantienen constantes las otras variables, las mujeres tienen un 8,5 por 100 más de probabilidades de tener lo que hemos llamado identidad dual que los hombres. En términos absolutos, y manteniendo las otras variables constantes, la probabilidad de que una mujer valenciana escogida al azar manifieste identidad dual es de 58,17 por 100, mientras que la de un hombre valenciano es de 49,71 por 100 .

Identificación con España. En la hipótesis se indica que la identificación fuerte con España puede derivar en un impacto negativo sobre la identidad dual. Esto quiere decir que se puede suponer que aquellas personas que no tengan una identificación fuerte con España (valor 0 en la variable correspondiente) tendrán más probabilidades de presentar una identidad dual que las que sí tienen una identificación fuerte con España. Los resultados de nuestros análisis no permiten corroborar esta hipótesis. Los valencianos que se identifican de una manera fuerte con España tienen una probabilidad de presentar una identidad dual del 46 por 100, mientras que los que tienen una identificación débil o media tienen una probabilidad del 43 por 100 . Esta diferencia del 3 por 100 es escasa y viene a mostrar que la identificación con España no es incompatible con mantener una identidad dual, de la misma manera que la identificación débil o media con la idea de España tampoco lo es.

La lengua. Con los resultados de nuestros análisis de la regresión logística podemos comprobar en qué medida la lengua es realmente un determinante de la identidad dual del individuo. Recuérdese que la variable «lengua» se refiere a la lengua materna del entrevistado. Existen tres categorías, de las cuales se excluye la de los bilingües para el análisis. De esta forma podemos descubrir la diferencia entre los bilingües y los castellanoparlantes en términos de probabilidad de presentar identidad dual o no. La conclusión más relevante es que el hecho de tener como lengua materna el valenciano no parece ser significativo a la hora de mostrar la identidad dual, ya que al no ser significativo, el coeficiente nos indica que no podemos rechazar la hipótesis nula $(b=0)$ y que, por tanto, su impacto en la identidad dual es nulo. Sin embargo, los datos que hemos obtenido del cálculo de probabilidades estimadas a partir de la ecuación de regresión logística nos indican que una persona que no tiene el castellano como lengua materna tiene un 69,2 por 100 de probabiliddes de presentar la identidad dual, mientras que una persona de lengua materna castellana tiene una probabilidad del 47,7 por 100 . En consecuencia, una persona cuya lengua materna no sea el castellano escogida al azar tiene un 21,4 por 100 más de pro- 
babilidades de presentar una identidad dual en comparación con los/as bilingües cuando las otras variables se mantienen constantes. Con estos resultados, para el caso valenciano se tiene que rechazar la versión primordialista de la lengua. No obstante, en la medida en que la lengua es un fenómeno multidimensional en el que se entremezclan tanto su uso como el prestigio de la misma y factores políticos, se debería explorar más a fondo estos resultados, quizá utilizando técnicas más cualitativas ${ }^{16}$.

Percepción de las autonomías. El factor 1 es una variable continua de media 0 y desviación 1 . Sus valores van de $-3,37$ a 1,78. Una puntuación alta significa que se tiene una percepción positiva del Estado de las Autonomías, mientras que una puntuación baja (negativa) indica que la percepción es negativa. Al tratarse de un factor las unidades de medida son difíciles de explicitar, por lo que el efecto de esta variable sobre la identidad dual tendrá que explorarse de alguna otra manera ${ }^{17}$. Asumiendo una relación lineal entre la variable independiente y la dependiente, se puede afirmar que a medida que aumenta la valoración positiva de las autonomías aumenta la probabilidad de presentar la identidad dual. Cada medida de aumento en el factor se corresponde con un incremento de la probabilidad de tener identidad dual del 9,7 por 100 .

Combinación de variables independientes. Interesa conocer el efecto combinado que puede tener la variable «nacimiento" para mujeres que hablan castellano y tienen una identificación fuerte con España, ya que éstas son las características más significativas respecto de la identidad dual. Realizados los cálculos pertinentes, resulta que las mujeres que han nacido en la Comunidad Valenciana, tienen el castellano como lengua materna y se identifican fuertemente con España tienen más probabilidades (48 por 100) de presentar la identidad dual que aquellas mujeres con las mismas características pero que han nacido fuera de la Comunidad Valenciana (30 por 100). De esto se deduce que una persona escogida al azar que haya nacido en la Comunidad Valenciana tiene un 18 por 100 más de probabilidades de presentar la identidad dual cuando concitan las características especificadas anteriormente (mujeres, de lengua castellana y fuerte identificación con España). Realizando los mismos cálculos pero cambiando la variable género (ahora masculino), tenemos que los nacidos en la Comunidad Valenciana tienen un 16 por 100 más de probabilidades de presentar la identificación dual cuando son hombres que hablan castellano y tienen una identificación fuerte con España.

Quizás interese conocer el efecto de la variable lengua materna castellana en la identidad dual para un valenciano/a que haya nacido en la Comunidad y tenga una identificación fuerte con España, independientemente de su género. En este caso, la probabilidad de que un no castellano hablante nacido en la

${ }^{16}$ Un excelente trabajo que combina técnicas cualitativas y cuantitativas es el de Woolard (1989).

17 Véase el apartado siguiente para un análisis del factor 1 y los efectos que recoge de otras variables que pueden tener un impacto final en la identidad dual. 
Comunidad Valenciana que se identifique fuertemente con España tenga identidad dual es de 61,9 por 100 , mientras que para una persona con las mismas características pero que tenga como materna la lengua castellana la probabilidad es de 39,7 por 100. La diferencia de probabilidades indica que los no castellano-hablantes tienen un 22 por 100 menos de probabilidades de presentar la identidad dual. En futuras investigaciones se debería prestar atención a esta diferencia al objeto de acotar mejor el impacto de la lengua en la identidad.

\section{LA VALORACIÓN DE LA ESTRUCTURA Y FUNCIONAMIENTO AUTONÓMICO}

La percepción y valoración que se hace de la distribución territorial del poder político influye en los procesos de identificación de los individuos. Fenómenos como la provincialización, la comarcalización o la creación de Comunidades Autónomas, incluso la aplicación de determinadas políticas públicas, generan, potencian o reducen identificaciones colectivas (Mira, 1984; Thompson y Rudolph, 1992).

En el apartado anterior hemos podido determinar que la valoración que se hace respecto a la estructura territorial autonómica, y su funcionamiento, tiene una influencia importante sobre la probabilidad de identificarse de forma dual, tan valenciano como español. De hecho, el factor 1 es la variable más significativa del modelo logístico comentado con anterioridad.

Sin embargo, nos encontramos con la dificultad técnica de explicar el contenido de este factor. Incluso existe la posibilidad de que recoja el efecto de otras variables, tanto las incluidas en el modelo como las excluidas. Por todo ello hemos creído conveniente profundizar un poco en la descripción y explicación de esta dimensión por medio de variables sociodemográficas.

El factor 1 recoge la información de las preguntas 40, 41, 42, 3901 y 3903 de la encuesta del CIS, todas ellas relacionadas con la valoración del entrevistado/a respecto al Estado de las Autonomías, su estructura y funcionamiento. Como quiera que la variable es de intervalo, cuantitativa, ya que es el resultado de la transformación lineal de las preguntas señaladas, hemos aplicado un modelo de regresión lineal. Además, sabemos que, por tratarse del resultado de un análisis factorial, el valor medio de la variable es 0 y su desviación estándar es igual a 1.

Como variables explicativas hemos introducido, por bloques, las siguientes variables dicotómicas (las mismas que en el modelo, excepto los factores): 


\section{CUADRO 4}

\section{Variables regresión lineal FAC1}

\begin{tabular}{|c|c|}
\hline $\begin{array}{l}\text { NAIX } \\
\text { SEXFEM }\end{array}$ & $\begin{array}{l}\text { Nacidos en la Comunidad Valenciana }=1 \text {, el resto }=0 \text {. } \\
\text { Mujer }=1 \text {, Hombre }=0 .\end{array}$ \\
\hline URBANA & Residente en municipio mayor de 100.000 h. $=1$, resto $=0$ \\
\hline SEMIRURA & Residente en municipio entre 10.000 y $100.000 \mathrm{~h} .=1$, resto $=0$ \\
\hline BILING & Dos lenguas maternas $=1$, resto $=0$ \\
\hline VALENCIA & Valenciano como lengua materna $=1$, resto $=0$ \\
\hline DIRECTIU & Directivos, propietarios y gerentes $=1$, resto $=0$ \\
\hline JEFES & Jefes, mandos intermedios, capataces $=1$, resto $=0$ \\
\hline TECNICS & Profesionales y técnicos $=1$, resto $=0$ \\
\hline AGRIC & Trabajadores agrícolas $=1$, resto $=0$ \\
\hline INDUS & Trabajadores industria $=1$, resto $=0$ \\
\hline MADJOV & Entre 25 y 44 años $=1$, resto 0 \\
\hline MADURO & Entre 45 y 64 años $=1$, resto 0 \\
\hline MAYOR & Más de 64 años $=1$, resto $=0$ \\
\hline PRIMARIO & Estudios primarios $=1$, resto $=0$ \\
\hline SECUNDA & Estudios secundarios o medios $=1$, resto $=0$ \\
\hline UNIVERS & Estudios superiores $=1$, resto $=0$ \\
\hline CENTESQ & Ubicación ideológica $3-5=1$, resto $=0$ \\
\hline CENTDRET & Ubicación ideológica $6-8=1$, resto $=0$ \\
\hline DRETA & Ubicación ideológica $9-10=1$, resto $=0$ \\
\hline DUALESTR & Identificación dual $(\mathrm{P} 18=3)=1$, resto $=0$ \\
\hline FVALENCIA & Identifcación fundamentalmente valenciana $(P 18=4,5)=1$, resto $=0$ \\
\hline PROFORTE & Identificación territorial con la provincia fuerte $=1$, resto $=0$ \\
\hline COMFORTE & Identificación territorial con la Com. Valenciana fuerte $=1$, resto $=0$ \\
\hline ESPFORTE & Identificación territorial con España fuerte $=1$, resto $=0$ \\
\hline FAC1 & $\begin{array}{l}\text { Factor 1. Valoración de la estructura y funcionamiento del Estado autonó- } \\
\text { mico. Dependiente. }\end{array}$ \\
\hline
\end{tabular}

Por tratarse de variables politómicas, hemos dejado fuera de la regresión una categoría de cada variable que nos servirá de contraste ${ }^{18}$. Así, los coeficientes obtenidos nos informarán sobre el impacto de la presencia de cada categoría. Los modelos de regresión lineal nos informan sobre el valor promedio

${ }^{18}$ La elección es arbitraria, aunque se ha intentado elegir aquellas que teóricamente esperábamos fueran significativas por contraste. 
esperado en la variable dependiente (valoración de la estructura y funcionamiento del Estado de las Autonomías en España) en función de un valor determinado de las variables independientes, que en este caso se limita a la presencia (valor 1) o ausencia (valor 0) de la categoría. Así, la constante nos informa del efecto esperado en el caso que ninguna de las categorías esté presente, mientras que los coeficientes B obtenidos para cada categoría nos informan del impacto esperado por la presencia de la categoría. Si el coeficiente no es significativo se tiene que interpretar como que el impacto diferencial entre la presencia de la categoría y su ausencia es nula y, por tanto, es una categoría no significativa en la explicación de la variable dependiente.

El resultado global se recoge en el Apéndice 1. En él ya podemos comprobar que la introducción de las categorías relativas a la ocupación y al nivel educativo no son significativas. Esto indica que sus coeficientes no serán diferentes de los obtenidos de haber introducido la categoría de control y, por tanto, que las diferentes ocupaciones y/o niveles educativos no señalan una valoración promedio diferencial, no añaden explicación de la varianza. Con la introducción de los nueve bloques de variables obtenemos un $\mathrm{R}^{2}$ del 14,6 por 100 , que se convierte en 10,8 por 100 si lo ajustamos. Es decir, podemos explicar casi un 11 por 100 de la varianza con este modelo. Igualmente, podemos señalar que las categorías referidas a la identificación colectiva, a la lengua materna y a la edad son las que mayor información nos aportan sobre la valoración individual del Estado de las Autonomías.

Si nos fijamos en los niveles de significatividad, y aceptamos como significativos aquellos que alcanzan el valor 0,1 , tenemos que no se espera una valoración promedio diferente de la estructura y funcionamiento del Estado de las Autonomías:

1. Entre hombres y mujeres.

2. Entre residentes en diferentes hábitats.

3. Entre aquellos individuos con distintas ocupaciones.

4. Entre aquellos individuos con diferentes niveles educativos.

Sin embargo, sí que podemos esperar una valoración promedio diferencial:

1. Entre los nacidos en la Comunidad Valenciana y los nacidos fuera.

2. Según sea la lengua materna.

3. Según sea la edad.

4. Entre los que tienen una ubicación ideológica u otra.

5. Según la identificación colectiva.

6. Según la identificación territorial.

Todo esto se confirma cuando consultamos los coeficientes obtenidos para cada una de las categorías introducidas en el análisis (cuadro 5). 


\section{CUADRO 5}

\section{Modelo lineal reducido}

Model Summary

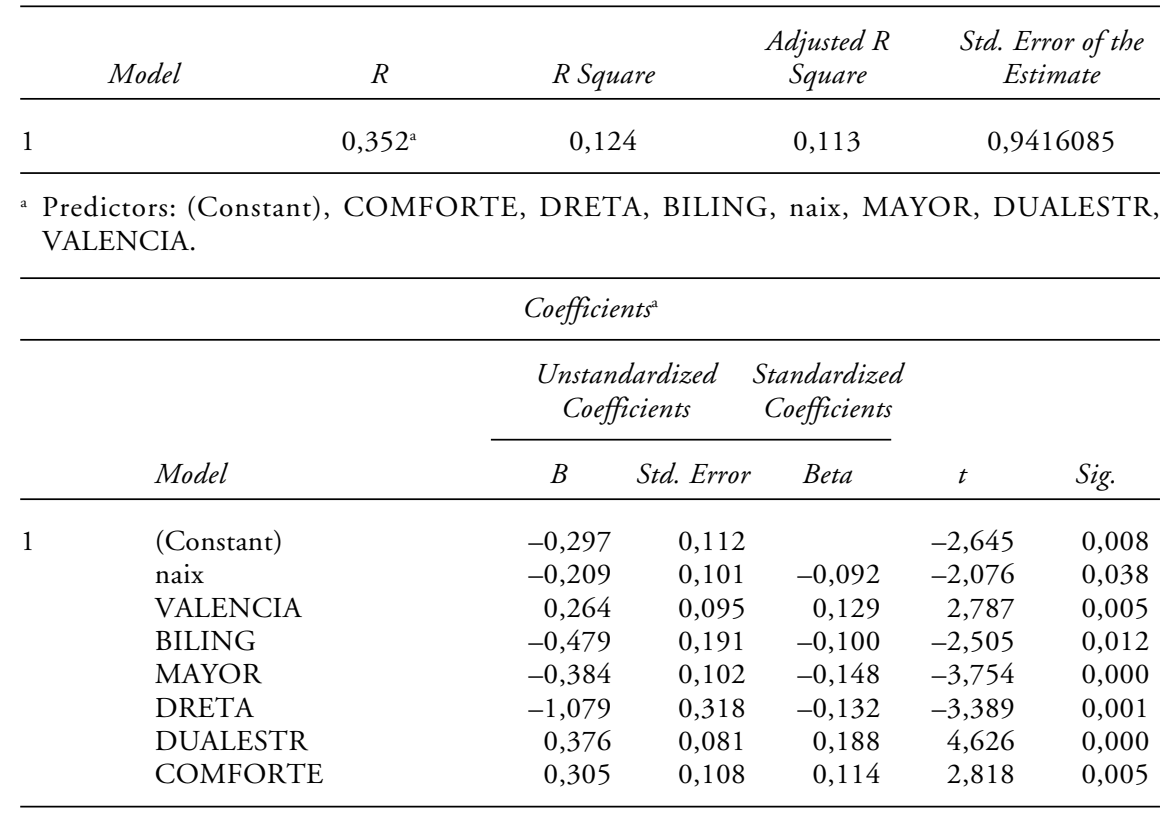

a Dependent Variable: REGR factor score 1 for analysis 1 .

Por ello, igual que hicimos en el modelo logístico, hemos tomado un modelo lineal reducido, con aquellas variables que son significativas. Un modelo con un $\mathrm{R}^{2}$ igual al 12,4 por 100 , pero que corregido es ligeramente superior al del modelo completo, con un 11,3 por 100 , lo que nos indica que no hemos perdido capacidad explicativa.

Si nos centramos en los coeficientes, el modelo resultante es el siguiente:

FAC1 $=-0,297-0,209$ NAIX $+0,264$ VALENCIA $-0,479$ BILING $-0,384$ MAYOR - 1,079DRETA + 0,376DUALESTR + 0,305COMFORTE

Esto significa que si ninguna de las categorías tiene valor 1, es decir, alguien no nacido en la Comunidad Valenciana, con el castellano como lengua materna, menor de 64 años, que no se ubica ideológicamente en la derecha, que no tiene una identificación colectiva dual estricta y no se identifica fuertemente con la Comunidad Valenciana, la valoración promedio esperada de la 
estructura y funcionamiento del Estado de las Autonomías es de -0,297. Alguien nacido en la Comunidad Valenciana valora, como promedio, 0,209 puntos menos el Estado de las Autonomías que alguien nacido fuera, mientras que alguien que tiene el valenciano como lengua materna lo valora 0,264 puntos más que alguien que no lo tiene.

De esta manera podemos afirmar que, como promedio, los que peor valoran la estructura y funcionamiento autonómico del Estado español son los nacidos en la propia Comunidad Valenciana, que tienen las dos lenguas como maternas, son mayores de 64 años, se ubican ideológicamente a la derecha y no tienen una identificación colectiva dual, ni se identifican fuertemente con la Comunidad Valenciana. Su puntuación media es de $-2,448$. Mientras que, de media, los que mejor lo valoran son los nacidos fuera de la Comunidad Valenciana, que tienen el valenciano como lengua materna, se identifican colectivamente de forma dual, son menores de 44 años, no se ubican ideológicamente a la derecha y se identifican fuertemente con la Comunidad Valenciana.

Por tanto, si bien en el modelo logístico establecido en el apartado III ni la edad ni la ubicación ideológica tenían poder explicativo de la identidad dual, después del análisis del FAC1, podemos sugerir que intervienen en el modelo a través de su influencia en la determinación de la valoración del Estado de las Autonomías. Las otras variables independientes, explicativas de FAC1, nos indican la interdependencia entre ellas a la hora de considerar el modelo logístico.

\section{CONCLUSIONES}

La primera conclusión que se debe extraer es que ni la ocupación, ni la educación, ni el hábitat, ni el hecho de tener el valenciano como lengua materna, ni la identificación fuerte con la provincia o con la Comunidad Valenciana, ni la ideología parecen tener un efecto significativo en el hecho de identificarse simultáneamente con la Comunidad Valenciana y con España (como valenciano y como español).

Sin embargo, en la medida en que la edad, la lengua materna valenciana, la identificación fuerte con la Comunidad Valenciana, el bilingüismo y la ideología intervienen en la explicación del factor 1 , se puede aventurar que estas variables pueden tener un efecto sobre la identidad dual a través del factor 1 . Éste es un aspecto que requiere un análisis posterior.

La segunda conclusión es que el género, la lengua materna castellana, la identificación fuerte con España, el lugar de nacimiento y la percepción positiva de las autonomías tienen un efecto claro en la identificación dual. Se tiene que resaltar que una variable clave como es el lugar de nacimiento es significativa tanto al 0,1 como al 0,5, e incluso al 0,01.

El que los nacidos en la Comunidad Valenciana y los que no tienen como lengua materna el castellano (es decir, tienen el valenciano o son bilingües) tengan mayor probabilidad de identificación dual parece indicar que, en el 
caso valenciano, la identidad dual crece más en detrimento de la identidad valenciana que de la identidad española.

\section{AGENDA DE INVESTIGACIÓN}

La limitación que necesariamente demanda un artículo aconseja dejar aquí nuestra investigación, aun siendo conscientes que quedan muchas cuestiones por investigar. De hecho, y como conclusiones añadidas, quedan abiertas al menos las siguientes líneas de investigación que pueden permitir extraer ideas más concluyentes:

1. Tendríamos que comprobar si los efectos que parece que se apuntan por interacción entre diversas variables son significativos o no. Con ello se podrían extraer conclusiones respecto a la interrelación entre las características demográficas a la hora de influir en los procesos de identificación colectiva en el caso valenciano.

2. Habría que realizar los mismos ejercicios de regresión para los casos de identidades en las que bien predomina la identidad española, bien lo hace la valenciana. Esto nos permitiría hacer comparaciones y extraer conclusiones tanto respecto a las probabilidades de identificación colectiva, en general, como respecto a la presencia, o no, de determinadas características, y sus efectos, sobre la valoración del Estado de las Autonomías.

3. Se debería realizar un ejercicio comparativo entre los modelos resultantes en el caso valenciano y los resultantes en otras Comunidades Autónomas. Esto permitiría poder concluir si el caso de los valencianos es un caso desviado, diferente, en el contexto español, o si realmente los modelos teóricos propuestos hasta el momento no dan las respuestas que explican los complejos procesos de identificación colectiva en el caso español.

\section{BIBLIOGRAFÍA}

Anderson, Benedict (1983): Imagined Communities. Reflections on the Origin and Spread of Nationalism, Londres: Verso.

ARIÑo, A., y Llopis, R. (1995): La identidad colectiva en la Comunidad Valenciana, V Congreso Español de Sociología, Granada (mimeo).

Brubaker, Rogers (1996): Nationalism Reframed. Nationhood and the national question in the New Europe, Cambridge: Cambridge University Press.

Carnero, Teresa, y Palafox, Jordi (1990): Geisiment, politització, i canvi social, 1790/1980, Valencia: Institució Alfons el Magnànim.

Deutsch, Karl (1966): Nationalism and Social Communication, New York: MIT Press.

Díez Nicolás, Juan (1999): Identidad nacional y cultura de Defensa», Madrid: Síntesis.

DiMaggio, Paul (1997): “Culture and Cognition», Annual Review of Sociology, vol. 23, pp. 263287.

FUSTER, Joan (1962): Nosaltres els valencians, València: Eliseu Climent Editor. 
García Ferrando, M.; López-Aranguren, E., y Beltrán, M. (1994): La conciencia nacional y regional en la España de las Autonomías, Madrid: CIS.

GeERTZ, Clifford (1973): The interpretation of cultures, Nueva York: Basic Books.

Gellner, Ernest (1983): Nations and Nationalism, Ithaca: Cornell University Press.

GUILLÉN, Mauro (1992): Análisis de regresión múltiple, Madrid: CIS.

Herranz de RAFAEl, Gonzalo (1996): «Estructura social e identificación nacionalista en la España de los noventa», REIS, núm. 76, pp. 9-35.

Hechter, M. (1989): "El nacionalismo como solidaridad de grupo», en Alfonso Pérez-Agote (ed.), Sociología del nacionalismo, Bilbao: Universidad del País Vasco.

Hobsbawm, Eric J. (1990): Nations and Nationalism since 1780. Programme, Myth, Reality, Cambridge (GB): Cambridge University Press.

Hroch, Miroslav (1985): Social preconditions of national revival in Europe, Cambridge: Cambridge University Press.

Jiménez Blanco, José; García Ferrando, Manuel; López Aranguren, Eduardo, y Beltrán VILlalVA, Miguel (1977): La conciencia regional en España, Madrid: CIS.

JOVELL, Albert J. (1995): Análisis de regresión logistica, Madrid: CIS.

LinZ, Juan J. (1973): «Early State Building and Late Peripheral Nationalisms Against the State: The Case of Spain", en S. N. Eisenstadt y Stein Rokkan (eds.), Building States and Nations. Analysis by Region, vol. II, Beverly Hills: Sage Publications, pp. 32-116.

- (1975): «Politics in a Multilingual society with a Dominant World Language: The Case of Spain», en J. G. Savard y R. Vigneault (comps.), Les états multilingues: problèmes et solutions, Quebec: Presses de l'Université de Laval, pp. 367-444.

- (1985): «From Primordialism to Nationalism», en Edward Tiryakian y Ronald Rogowski (eds.), New Nationalisms of the Developed West: Toward Explanation, Boston: Allen \& Unwin, pp. 203-53.

- (1989): "Spanish Democracy and the Estado de las Autonomías», en Robert A. Goldwing et al., Forging unity out of Diversity, Washington: American Entreprise Institute for Public Policy Research.

LÓPEZ-ARANGUREN, Eduardo (1981): «Regionalismo e integración nacional: aproximación teórica», REIS, núm. 15, pp. 59-76.

- (1995): "Las dimensiones de la conciencia nacional y regional», REIS, núms. 71-72, pp. 4177.

MirA, Joan F. (1984): Crítica de la nació pura, València: Tres i Quatre.

Mollà, Damià, y Mira, Eduard (1986): De Impura Natione, València: Tres i Quatre.

Moreno, Luis (1997): La federalización de España. Poder politico y territorio, Madrid: Siglo XXI.

MOYA, Carlos (1984): "Identidad colectiva: un programa de investigación científica», REIS, núm. 25, pp. 7-35.

NinYOLES, Rafael L. (1969): El conlicte lingüístic valencià, València: Tres i Quatre.

- (1971): Idioma I prejudici, València: Tres I Quatre.

PÉReZ-Agote, Alfonso (1984): La reproducción del nacionalismo. El caso vasco, Madrid: CIS.

Pérez Agote, Alfonso, y Tejerina, Benjamín (1990): «Lengua y actor social. Un enfoque teórico de sus relaciones», REIS, núm. 49, pp. 145-160.

PIQUeras, Andrés (1996): La identidad valenciana, Madrid: Escuela Libre Editorial.

Puhle, Hans-Jürgen (1993): «Nation States, Nations and Nationalisms in Western and Southern Europe», ponencia presentada en el Congreso titulado Os Nacionalismos en Europa, Santiago de Compostela, septiembre.

ROGOWSKI, Ronald (1985): "Causes and varieties of nationalism», en Edward A. Tiryakian y Ronald Rogowski (eds.), New Nationalisms of Developed West: Toward Explanation, Boston: Allen and Unwin.

SANCHIS GUARner, M. (1994 [1967]): La llengua dels valencians, València: Eliseu Climent Ed. (18. ${ }^{\mathrm{a}}$ ed.).

Tejerina, Benjamín (1992): Nacionalismo y lengua. Los procesos de cambio lingüistico en el País Vasco, Madrid: CIS-Siglo XXI. 
Thompson, Robert, y Rudolph, Josep R. (1992): Politica etnoterritorial, Barcelona: PomaresCorredor.

VArshney, Ashutosh (1993): "Contested Meanings: India's national Identity, Hindu Nationalism, and the Politics of Anxiety", Daedalus, vol. 122, núm. 3, pp. 227-261.

Woolard, Kathryn A. (1989): Double talk. Bilingualism and the Politics of Identity in Catalonia, Stanford: Stanford University Press.

\section{APÉNDICES}

Apéndice 1: Regresión lineal. Modelo Completo

Coefficients $^{\mathrm{a}}$

\begin{tabular}{|c|c|c|c|c|c|}
\hline & \multicolumn{2}{|c|}{$\begin{array}{c}\text { Unstandardized } \\
\text { Coefficients }\end{array}$} & \multirow{2}{*}{$\begin{array}{c}\begin{array}{c}\text { Standardized } \\
\text { Coefficients }\end{array} \\
\text { Beta } \\
\end{array}$} & \multirow[b]{2}{*}{$t$} & \multirow[b]{2}{*}{ Sig. } \\
\hline & $B$ & Std. Error & & & \\
\hline (Constant) ........................ & $-0,308$ & 0,289 & & $-1,065$ & 0,287 \\
\hline naix & $-0,214$ & 0,107 & $-0,095$ & $-2,009$ & 0,045 \\
\hline sexfem & 7,621E-02 & 0,080 & 0,038 & 0,955 & 0,340 \\
\hline URBANA ..................... & $-0,101$ & 0,116 & $-0,048$ & $-0,872$ & 0,384 \\
\hline SEMIRURA .................. & 2,296E-02 & 0,107 & 0,011 & 0,215 & 0,830 \\
\hline VALENCIA .................. & 0,251 & 0,103 & 0,122 & 2,432 & 0,015 \\
\hline BILING ...................... & $-0,486$ & 0,197 & $-0,101$ & $-2,465$ & 0,014 \\
\hline DIRECTIU ................. & $-0,174$ & 0,185 & $-0,039$ & $-0,937$ & 0,349 \\
\hline JEFES ............................ & 0,223 & 0,240 & 0,038 & 0,928 & 0,354 \\
\hline TECNICS ................... & $-8,545 \mathrm{E}-02$ & 0,166 & $-0,024$ & $-0,515$ & 0,606 \\
\hline AGRIC ...................... & 0,161 & 0,137 & 0,056 & 1,170 & 0,242 \\
\hline 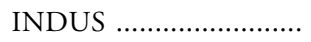 & $5,084 \mathrm{E}-02$ & 0,099 & 0,025 & 0,512 & 0,609 \\
\hline MADJOV ...................... & $-6,510 \mathrm{E}-02$ & 0,133 & $-0,027$ & $-0,490$ & 0,625 \\
\hline MADURO .................... & $-0,180$ & 0,126 & $-0,090$ & $-1,433$ & 0,152 \\
\hline MAYOR ....................... & $-0,571$ & 0,157 & $-0,220$ & $-3,627$ & 0,000 \\
\hline PRIMARIO ................. & $-8,982 \mathrm{E}-02$ & 0,124 & $-0,045$ & $-0,727$ & 0,468 \\
\hline SECUNDA ................... & $-0,159$ & 0,156 & $-0,065$ & $-1,022$ & 0,307 \\
\hline UNIVERS .................... & $5,475 \mathrm{E}-02$ & 0,191 & 0,017 & 0,286 & 0,775 \\
\hline CENTESQU ............... & 0,158 & 0,168 & 0,075 & 0,939 & 0,348 \\
\hline CENTDRET .............. & $7,156 \mathrm{E}-02$ & 0,179 & 0,032 & 0,401 & 0,689 \\
\hline DRETA ........................ & $-0,875$ & 0,359 & $-0,107$ & $-2,439$ & 0,015 \\
\hline DUALESTR ................. & 0,358 & 0,093 & 0,178 & 3,860 & 0,000 \\
\hline FVALENCI $. . . . \ldots \ldots \ldots \ldots . . . . .$. & $2,613 \mathrm{E}-02$ & 0,147 & 0,008 & 0,178 & 0,859 \\
\hline PROFORTE ............... & $-3,347 \mathrm{E}-02$ & 0,173 & $-0,012$ & $-0,193$ & 0,847 \\
\hline COMFORTE ............... & 0,291 & 0,170 & 0,109 & 1,708 & 0,088 \\
\hline ESPFORTE .................. & 0,117 & 0,120 & 0,042 & 0,976 & 0,329 \\
\hline
\end{tabular}

a Dependent Variable: REGR factor score 1 for analysis 1. 


\title{
El listado de variables y sus valores es el siguiente:
}

\begin{tabular}{|c|c|}
\hline Nacimiento & Lugar de nacimiento. $1=$ Comunidad Valenciana; $0=$ Resto (inmigrantes) \\
\hline Género & Sexo del entrevistado. $1=$ Mujeres; $0=$ Hombres \\
\hline Hábitat & Tamaño del lugar de residencia. $1=$ rural; $2=$ semirrural; $3=$ urbano \\
\hline Lengua & Lengua materna. $1=$ castellano; $2=$ valenciano; $3=$ bilingue \\
\hline Ocupación & $\begin{array}{l}1 \text { = Directivos, propietarios, gerentes; } 2=\text { Jefes, mandos intermedios, } \\
\text { capataces; } 3 \text { = Profesionales y técnicos; } 4=\text { Trabajadores en la agricultura } \\
5 \text { = Trabajadores de la industria y la construcción; } 6=\text { Trabajadores de } \\
\text { sector servicios }\end{array}$ \\
\hline Edad & $\begin{array}{l}1=\text { Joven }(18-24 \text { años }) ; 2=\text { Maduro joven }(25-34) ; 3=\text { maduro }(35-65) \\
4=\text { Mayor }(65 \text { y más años) }\end{array}$ \\
\hline Estudios & $\begin{array}{l}\text { Grado de educación conseguida. } 1=\text { Analfabetos y primaria incompleta } \\
2=\text { Primarios; } 3=\text { Secundaria; } 4=\text { Universitarios }\end{array}$ \\
\hline Ideología & $\begin{array}{l}\text { Ubicación en la escala ideológica. } 1 \text { = izquierda; } 2=\text { centro-izquierda; } 3= \\
\text { centro-derecha; } 4=\text { derecha }\end{array}$ \\
\hline Proforte & $\begin{array}{l}\text { Identificación provincial fuerte (corresponde a la suma de los valores } 8,9 \\
\text { y } 10 \text { de la ubicación del entrevistado/a en la escala de identificación 1-10) } \\
1=\text { Sí; } 0=\text { No }\end{array}$ \\
\hline Comforte & $\begin{array}{l}\text { Identificación con la CV fuerte (corresponde a la suma de los valores } 8,9 \\
\text { y } 10 \text { de la ubicación del entrevistado/a en la escala de identificación 1-10) } \\
1=\text { Sí; } 0=\text { No }\end{array}$ \\
\hline Espforte & $\begin{array}{l}\text { Identificación con España fuerte (corresponde a la suma de los valores } 8,9 \\
\text { y } 10 \text { de la ubicación del entrevistado/a en la escala de identificación } \\
1-10) .1 \text { = Sí; } 0=\text { No }\end{array}$ \\
\hline Factor 1 & Valoración del Estado de las Autonomías \\
\hline Factor 2 & Consideracón de la unidad nacional española \\
\hline Factor 3 & Adhesión afectiva a España \\
\hline Factor 4 & Centralismo estatal \\
\hline Factor 5 & Autonomía política \\
\hline DUMID3 & Identidad dual. 1 = Sí; $0=$ No (variable dependiente) \\
\hline
\end{tabular}

\begin{abstract}
Theories regarding nationalism and collective identities, particularly new institutionalist theory, foresee the flourishing and consolidation of regional identities as a result of the federalisation of states and the emergence of institutionalised political units. This is more likely to occur where cultural, economic and/or political conditions pave the way for the shaping of the belief in "differentiation». The Valencian case deviates from this norm: rather than the regional, peripheral (or national) identity having been strengthened, a multiple identity has been consolidated capable of combining the Spanish and Valencian collectives which serve as a benchmark. This paper examines the social foundations of this dual identity and attempts to develop an explicative model for this phenomenon, which merits closer inspection as a result of the decentralisation of states.
\end{abstract}

